\title{
GRAU DE ESTABILIDADE DAS VERTENTES DA SERRA DO PURUNÃ NAS PROXIMIDADES DO FALSO TÚNEL
}

Cristiane do Amaral ${ }^{*}$

\author{
DISSERTAÇÃO DE MESTRADO - Programa de Pós-Graduação em Geologia - UFPR \\ DATA DE DEFESA: 03 out. 2003
}

\begin{abstract}
Apresenta-se uma síntese dos estudos de estabilidade das vertentes e do movimento de massa realizados na subida da Serra de São Luiz do Purunã, rodovia BR-277, sentido Curitiba/Ponta Grossa. A partir da metodologia empregada, levantamento de dados de campo e análises laboratoriais foram feitas juntamente com a revisão dos conceitos referentes à estabilidade de talude, cálculos de fatores de segurança de vertentes pelo emprego das equações que levam em conta diferentes parâmetros físicos e mecâ-
\end{abstract}

nicos dos solos (coesão, ângulo de atrito, peso específico, além do nível freático, forma de fluxo d'água e efeitos da vegetação). Vários mapas temáticos (drenagem, altimétrico, hipsométrico, declividade, geológico) foram elaborados, e a partir destes, com o emprego de modelos matemáticos de estabilidade de taludes, elaborou-se o mapa de Índices de Segurança. Posteriormente, foi feita uma avaliação da intensidade crítica de chuvas necessária para deflagrar o processo de ruptura de vertentes. 